REVISTA CHILENA DE LITERATURA

Noviembre 2015, Número 91, 11-24

\title{
SI LOS HOMBRES FUERAN BUENOS... ANTROPOLOGÍA DEL ANTIPOEMA
}

\author{
Antonio Melis \\ Universidad de Siena \\ antonio.melis@unisi.it
}

RESUMEN / ABSTRACT

El ensayo trata de examinar en términos dialécticos la relación entre poesía y antipoesía en la obra de Nicanor Parra. Cuando el poeta se despide de la poesía para ingresar a la antipoesía, lo hace después de rendir un último homenaje a una práctica agotada. El enfrentamiento con la modernidad procede de un impulso ético. El rechazo del idilio nace de la comprobación de su imposibilidad. Asimismo se combate la idea de que exista un lenguaje poético ya definido, que garantiza la calidad literaria. La crítica del lenguaje codificado se une al rechazo de toda visión endulzada de la realidad. La desacralización sistemática de todos los valores ha provocado contra el poeta la acusación de cinismo. Pero la imposibilidad de creer en algo no es un capricho, sino una condición dramática vivida con coherencia. De allí la analogía con la amarga consideración de Niccolò Machiavelli, cuando denuncia la maldad del ser humano. Esto no impide, sin embargo, el reconocimiento de que se trata de un ser destinado al sufrimiento y a la muerte. De allí la compasión del hombre y del poeta, que había ingresado con confianza en el mundo de las palabras encantadas, para comprobar su disolución frente al horror de lo moderno.

PalABRAS Clave: antipoesía, antropología, léxico, pesimismo, compasión.

The paper attempts to examine dialectically the relationship between poetry and anti-poetry in the work of Nicanor Parra. When the poet takes leave of poetry to enter antipoetry, it makes after paying last respects to a dead practice. The confrontation with modernity comes from an ethical impulse. The rejection of the affair stems from their inability checking. The idea that there is a definite and poetic language, which guarantees the literary quality is also fighting. Criticism of coded language joins the rejection of all sweetened vision of reality. The systematic desecration of all values has led the charge against the poet of cynicism. But the inability to believe in something is not a fad, but a dramatic condition lived coherently. Hence the analogy with the bitter consideration Niccolo Machiavelli, when denouncing the 
wickedness of man. This does not, however, recognize that it is a being destined to suffering and death. Hence the compassion of the man and the poet, who had confidently entered the enchanted world of words, to check its dissolution against the horror of the modern.

KEY WORDS: antipoetry, anthropology, lexicon, pessimism, compassion.

"Se gli uomini fussino tutti buoni $[\ldots]$ ma perché sono tristi $[\ldots] " 1$

Esta referencia a uno de los pasajes más conocidos del tratado político de Niccolò Machiavelli puede parecer raro en un ensayo dedicado a la poesía de Nicanor Parra. Pero creo que en esta cita se encuentra una clave posible para examinar bajo una nueva luz la dialéctica entre poesía y antipoesía que encontramos en la obra del poeta chileno. Desde este punto de vista, el libro Poemas y antipoemas representa la piedra de toque de esta hipótesis, a partir de su división interna señalada claramente por el título. Es un libro que aparece después de un largo silencio editorial, a 17 años de distancia de Cancionero sin nombre, y que representa, en su doble cara, el resultado de una batalla poética y humana compleja.

En la primera parte de la colección, asistimos a una forma de adiós a la poesía tradicional. Tal vez la síntesis de esta despedida se encuentre en el poema "Hay un día feliz", desde el punto de vista estilístico y a partir de su propio contenido. El tema es un verdadero topos: el regreso a la aldea natal, que sirve para comprobar los estragos producidos por el tiempo. En el tratamiento de este tema clásico, casi tan antiguo como la misma poesía, se registra una continua alternancia entre el idilio y la constatación de su agotamiento e imposibilidad. O sea, en otras palabras, entre la poesía y la antipoesía ${ }^{2}$.

El autor se despide de la poesía para ingresar en la antipoesía, pero lo hace ofreciendo un homenaje extremo a un tipo de práctica literaria que

1 N. Machiavelli. Il Principe [1514]. Milano: Mondadori, 1994, p. 77. ("Si los hombres fueran todos buenos [...] pero puesto que son malvados [...]").

Para la exégesis de este poema sigue siendo imprescindible el ensayo de F. Schopf, "La escritura de la semejanza en Nicanor Parra". Revista Chilena de Literatura 2-3 (1970): 43-132. 
resulta imposible mantener. El mundo representado hasta el pasado reciente se ha venido abajo y hay que enfrentarse con una modernidad arrasadora. La "blanca tempestad de arena"3 que ha cubierto la aldea de su infancia significa que una edad de la vida, individual y colectiva se ha acabado para siempre.

De allí la necesidad ineludible de enfrentarse con una realidad áspera y dolorosa, sin ningún fingimiento consolatorio. Simular que nada haya ocurrido representaría una mentira, por lo demás inútil y patética. Registrar esta nueva condición procede de un impulso profundamente ético, que alimenta toda su trayectoria sucesiva y que desmiente cualquier interpretación barata, fundada en el supuesto "cinismo" del poeta.

Parra coincide, en esta elección de un camino arduo, con una afirmación contenida en una entrevista de otro gran escritor hispanoamericano, el guatemalteco Augusto Monterroso. Contestando a una pregunta sobre la literatura comprometida, sugiere una interpretación más radical respecto a la visión corriente:

Usted ve que Dostoievski vuelve a ser editado en su patria, y Kafka considerado, por fin, un crítico del capitalismo. Sea cuál haya sido su posición frente a los regímenes en que les tocó escribir, lo que no parece entenderse es que ninguno de los dos estaba en lo fundamental descontento con ningún sistema político, sino como todo buen escritor, como Cervantes y como Swift, con el género humano, simple y sencillamente ${ }^{4}$.

Esta posición radical es uno de los fundamentos de la nueva poesía de Parra, a partir de su alejamiento del idilio. Seguir cultivando una visión positiva del mundo le parecería una mentira piadosa hacia el lector. Y es evidente que entre los rasgos fundamentales del antipoema figura una actitud que no quiere ser conciliante con el interlocutor. De allí proceden también sus conocidas advertencias al lector, para que la relación establecida con él no tenga ninguna ambigüedad:

3 N. Parra. "Hay un día feliz". Poemas y antipoemas. Ed. de R. de Costa. Madrid: Ediciones Cátedra, 1988, p. 61.

${ }_{4}$ A. Monterroso. Viaje al centro de la fábula [1981]. Barcelona: Muchnik Editores, 1990, p. 31. 
Según los doctores de la ley este libro no debiera publicarse:

La palabra arco iris no aparece en él en ninguna parte,

Menos aún la palabra dolor,

La palabra torcuato ${ }^{5}$.

Aquí se rechaza rotundamente la idea de que pueda existir un lenguaje poético ya definido, cuya presencia en los versos es una garantía de calidad literaria. Los tres ejemplos escogidos, bastante heterogéneos, resultan muy significativos. El arco iris alude al repertorio de los colores, como elemento típico del discurso poético. Con la palabra dolor entramos en otra clase de nomenclatura consolidada, la que se refiere a la esfera de los sentimientos. Más singular es indudablemente el último ejemplo: un nombre de persona bastante raro, que por eso mismo, tal vez, parece conferir un aura poética al texto, según la visión tradicional del lenguaje alto.

Pero, al lado de la parodia lexical, en esta sección del libro aparecen asimismo los elementos de una crítica radical a toda visión idílica de la realidad. Piénsese, por ejemplo, en un poema como "Oda a unas palomas". En él asistimos a la progresiva subversión, desde adentro, de una figura generalmente asociada, en la literatura universal, a la bondad y al cariño. Al comienzo, el poema parece seguir los caminos acostumbrados de esta simbología, aunque se asoma inmediatamente un detalle ("sus enormes vientres redondos"), que introduce un aspecto contradictorio. En el desarrollo del poema se define cada vez más el perfil auténtico de esos seres generalmente idealizados. Ellos son en realidad el compendio de todos los vicios, puesto que tienen

El olfato del zorro,

La inteligencia fría del reptil

Y la experiencia larga del loro ${ }^{6}$.

La desacralización de las figuras oficiales afecta al mismo tiempo la esfera civil y la esfera religiosa, a través de la denuncia de la hipocresía que acomuna al profesor con el "abad que se cae de gordo". Al fin y al cabo, el objetivo de todos esos personajes es, como aclara un verso agregado a partir de ediciones sucesivas a la primera, apoderarse de la caja de fondos.

\section{N. Parra. Poemas y antipoemas, cit., p. 81.}

Ibíd., p. 76. 
Esta actitud de revelación y denuncia de la otra cara de la moneda se registra asimismo frente a las manifestaciones de la religiosidad. En "San Antonio", la mortificación ascética de la carne no llega a ocultar las pasiones oscuras y turbias que animan al eremita. Hasta que al final ellas encuentran su resumen en los siete pecados capitales que el ermitaño lleva grabados en la frente.

Para que no haya equivocaciones sobre el sentido profundo que tiene este viraje, el desencanto y la crítica se aplican en primer lugar al propio sujeto poético. El "Autorretrato", por ejemplo, es una acumulación de detalles desagradables, físicos y síquicos, aunque ellos son el resultado de una vida destruida por el exceso de trabajo. Al mismo tiempo, el poema se dedica a desmitificar el ambiente de la escuela, exaltado muchas veces por una literatura edificante y dulzona. Sobre este mismo tema, pero con un enfoque a partir del punto de vista del alumno, volverá más tarde en el largo poema "Los profesores" mnemónico y fósil impuesto por la escuela y las urgencias planteadas por la vida personal y colectiva. El "Epitafio" representa un complemento del "Autorretrato", culminando en la célebre autodefinición como "iUn embutido de ángel y bestia!"

En la demolición sistemática del idilio juega un papel importante la desmitificación de la institución familiar. "El túnel", a través de las figuras de las tías con las que tienen que convivir y que lo explotan descaradamente, representa este descubrimiento traumático. La revelación de la impostura de una de ellas es otro momento de una toma de conciencia que lleva a una actitud de escepticismo total. La culminación de este proceso se encuentra, desde luego, en "La víbora", porque en este poema el poeta ataca directamente la representación acostumbrada del amor. Fuera de la excitación sexual momentánea, se trata de una relación fundada solamente en el mero interés económico. "La trampa", desde el mismo título del poema, alude a los engaños de la vida, que esta vez se identifican con las conversaciones telefónicas de tipo neurótico que el sujeto poético mantiene con la mujer amada.

En el largo poema "Los vicios del nundo moderno" el extenso catálogo de las degeneraciones que se han ido produciendo en la vida humana parece, sin embargo, encontrar al final un posible antídoto. Aquí aparece un llamado

\footnotetext{
$34-41$.

N. Parra. Hojas de Parra. Santiago de Chile: Ediciones Ganymedes, 1985, pp.

N. Parra. Poemas y antipoemas, cit., p. 77.
} 
al instinto vital, sobre todo al eros, aunque al final el texto deja entrever, una vez más, la decepción:

Por todo lo cual

Cultivo un piojo en mi corbata

Y sonrío a los imbéciles que bajan de los árboles 9 .

El "Soliloquio del Individuo", que cierra el poemario, es un resumen de la historia humana y de su total insensatez. Frente a la perspectiva de emprender otra vez el mismo camino desde el comienzo, la conclusión es drástica:

Pero no: la vida no tiene sentido ${ }^{10}$.

El sinsentido de la vida es una constante que recorre toda la producción sucesiva. Pero esta actitud, al mismo tiempo, no agota su repertorio poético. En La cueca larga se apoya totalmente en la tradición popular, un elemento destinado a alimentar con continuidad su poesía, hasta los años más recientes. El tema del vino insinúa una forma de sociabilidad que se opone a las relaciones acostumbradas entre los hombres de la sociedad moderna, fundadas en el dominio. Pero se trata de un oasis efímero, que muy pronto deja el lugar al regreso de una realidad hostil.

En Versos de salón vuelve a relacionarse, en forma una vez más agonista, con su propio lector. La metáfora de la montaña rusa sirve para rematar el riesgo que conlleva para el destinatario la experiencia de la antipoesía. Para acabar de una vez con "el paraíso del tonto solemne", es preciso ponerse en juego totalmente, con el riesgo de bajar "echando sangre por boca y narices". La subversión empieza, una vez más, a partir de la palabra. "Cambio de nombre" presenta una nueva versión de la función adánica. A la facultad del primer hombre, según el cuento bíblico, de dar el nombre a las cosas captando su esencia íntima, se sustituye la posibilidad arbitraria de cambiar los nombres, como acto de insubordinación contra el orden establecido del lenguaje.

En el terreno de la poética, se remata explícitamente la plena vigencia de la antipoesía. De allí su nueva "Advertencia", esta vez intencionalmente agresiva hacia el lector:

$\begin{array}{ll}9 & \text { Ibíd., p. } 110 . \\ 10 & \text { Ibíd., p. } 116 .\end{array}$ 
Yo no permito que nadie me diga

Que no comprende los antipoemas

Todos deben reír a carcajadas ${ }^{11}$.

Aquí aparece otro motivo constante de la antipoesía, o sea, la alusión a la risa, esa risa que Rabelais, uno de los autores subyacentes a los poemas de Parra, consideraba como el rasgo típico del hombre. La risa es asimismo el antídoto mejor contra el ya evocado "tonto solemne" y representa un elemento firme contra todo autoritarismo, en la vida como en la literatura.

La risa, muchas veces amarga y a veces perteneciente al humor negro, triunfa en la etapa sucesiva de la antipoesía, donde se registra un cambio decisivo de los instrumentos expresivos. Con Artefactos, Parra se aleja aún más de la tradición, introduciendo un contrapunto visual a sus palabras o a las palabras que asume como propias. Dentro de esta auténtica revolución en la revolución, el tema político adquiere un relieve creciente y es uno de los mayores motivos de escándalo en la época de su publicación. El poeta se mantiene coherentemente contracorriente, a pesar de los cambios políticos que ocurren, desafiando así la impopularidad. Uno de los ejemplos más conocidos es la parodia de la consigna, universalmente conocida, que había caracterizado la campaña electoral de la Unidad Popular. En una pancarta que encabeza una manifestación, el lema "El pueblo unido jamás será vencido" se transforma así en "La izquierda y la derecha unidas jamás serán vencidas" ${ }^{\prime 2}$. Frente a las reacciones de condena provocadas entre los militantes de la época, sería demasiado fácil subrayar el carácter profético que esta provocación ha ido adquiriendo con el trascurso del tiempo, como lo revelan las coaliciones heterogéneas y postideológicas que han asumido en años recientes el gobierno de varios países del mundo. Pero se trata de un aspecto secundario, frente al significado profundo del artefacto, cuya finalidad, más allá de la contingencia, es sobre todo la de rechazar el lenguaje simplificado, en nombre de una actitud crítica permanente. En la misma línea se colocan otras alusiones a la actualidad política del país, que tienen asimismo un significado universal. "Para ser Presidente hay que ser escupido previamente" es la manifestación de una actitud intransigente, antipolítica,

11 N. Parra. Obra gruesa. Santiago de Chile: Editorial Andrés Bello, 1983, p. 67.

12 N. Parra. Artefactos. Santiago de Chile: Ediciones Nueva Universidad, 1972, s.p. Todas las citas se refieren a esta edición. 
que rechaza la perspectiva del poder, porque considera que para conseguirlo hay que aceptar transacciones intolerables. "Adonde cantan / y bailan los poetas / no te metas Allende / no te metas", son las palabras que comentan la visión de un grupo de gente que se divierte. Aquí, más allá de la referencia contingente al futuro Presidente de Chile, lo que está en juego es la defensa de la autonomía de la literatura frente a cualquier interferencia, aunque bien intencionada, del poder. Contra toda sospecha de dirigismo cultural, proclama también con orgullo su voluntad de no hacerse manipular: "A mí nadie me pisa los callos / A mí nadie me pasa a llevar / Aunque sea Fidel en persona / O la propia Unidad Popular".

Al mismo repertorio pertenece otro artefacto "escandaloso" en el momento de su aparición, el que propone una variante de la consigna antimperialista "Cuba sí, yankees no" en "Cuba sí, yankees también". En este caso sería asimismo reduccionista interpretar la provocación solo como una respuesta al conflicto provocado con Casa de las Américas, causado por la ya célebre taza de té con la esposa de Nixon. Más allá de estos detalles vinculados con la época, lo que sobresale es una actitud irreductible de rechazo frente a toda fórmula simplista. Por lo que se refiere a su actitud frente al proceso cubano, tal vez se pueda encontrar una iluminación importante en otro artefacto, el que dice: "Perdón sí, paredón no".

Asimismo sería arbitrario aislar estos productos, que provocaron tantas polémicas en su momento, de otros artefactos que, en forma incluso más contundente, golpean en una dirección opuesta. Piénsese sobre todo en el dibujo muy elemental que representa la Estatua de la Libertad, acompañada por ese comentario sintético y feroz: "USA donde la libertad es una estatua". La desmitificación del lenguaje, a través del contraste entre las palabras y la realidad, es el alimento constante de este libro. En la gran mayoría de los casos, el efecto contundente se obtiene con una economía extremada de medios expresivos. Por ejemplo, el artefacto que reproduce las grandes palabras de los valores universales proclamados por la Revolución francesa ("Libertad Igualdad Fraternidad"), está ilustrado por escenas de violencia e injusticia que contradicen totalmente el enunciado verbal. En la misma dirección se sitúa la tarjeta dividida en dos partes: en la primera se ve una escena de guerra acompañada por la consigna, siempre actual en su empleo justificacionista, "Fighting for Peace", en la segunda una escena erótica ilustrada por las palabras simétricas "Fucking for Chastity". El mismo esquema contrastivo, esta vez vinculado con la dimensión cultural, se encuentra en el 
artefacto donde desde un teléfono sale esta conversación: “Aló con la Casa de la Cultura? Sí Conchetumadre".

Para terminar ese breve recorrido entre los "Artefactos", quisiera recordar uno de ellos que resulta sumamente significativo de la actitud profunda del poeta, frente a toda simplificación barata acerca de su supuesto "cinismo". Es un texto dedicado a Ernesto Che Guevara que dice: "Perdona la franqueza / Hasta la estrella de tu boina / "Comandante" me parece dudosa / Y sin embargo se me caen las lágrimas". Por un lado, encontramos el rechazo del cliché, que se ha apropiado rápidamente de la figura del Che, tranformándolo de esta manera en un producto comercial. Por el otro, registramos el respeto y la conmoción profunda hacia un hombre coherente con sus principios, que en nombre de ellos se ha jugado la vida.

En este último ejemplo aparece un aspecto contradictorio con respecto a la imagen iconoclasta del poeta que él mismo ha promocionado. Pero no se olvide, como prueba de que le cuerda de la ternura, a pesar de todo, ha quedado presente o por lo menos latente en su obra, el magnífico poema escrito con ocasión del suicidio de su hermana. La imagen del "corderillo disfrazado de lobo"13 que sirve para caracterizar cariñosamente a Violeta, puede aplicarse legítimamente al mismo Nicanor.

Una ternura de tipo diferente es la que se encuentra, junto a elementos abiertamente cómicos, en el ciclo dedicado al Cristo de Elqui. A través de este singular alter ego del poeta -un personaje real de los años veinte- Parra introduce otro aspecto de la cultura popular, el de los visionarios y profetas, en cuya predicación los grandes temas religiosos se mezclan con consejos prácticos para la vida diaria. Pero, sobre todo, a través de ese disfraz, el poeta llega a transmitir mensajes alusivos, a veces en forma explícita, a la opresión que está viviendo el país bajo la dictadura militar.

Desde el punto de vista de la antropología poética, en la producción de los últimos años ocupa un lugar decisivo Hojas de Parra, que reúne textos de épocas diferentes. Uno de los poemas más representativos de su escepticismo coherente y radical es el siguiente:

13 N. Parra, Obra gruesa, cit., pp. 161-166. 


\author{
NO CREO EN LA VIA PACIFICA \\ no creo en la vía violenta \\ me gustaría creer en algo -pero no creo \\ creer es creer en Dios \\ lo único que yo hago \\ es encogerme de hombros \\ perdónenme la franqueza \\ no creo ni en la Vía Láctea ${ }^{14}$.
}

El elemento fundamental de este poema es obviamente la repetición (cuatro veces) del sintagma "no creo". La última vez se registra, además, un salto lógico típico de la antipoesía, desde el dilema sobre el camino más adecuado para la revolución latinoamericana (en los términos típicos de los años sesenta y setenta) hasta una dimensión cósmica. Pero no hay que olvidarse de otro sintagma, que puede pasar desapercibido en medio del humor negro que domina el poema. Me refiero a la frase donde el sujeto poético confiesa "me gustaría creer en algo". Es una confesión importante, porque significa que la imposibilidad de creer no es un capricho para llamar la atención del lector, sino una condición dramática asumida con plena responsabilidad y coherencia. Un vez más, "Si los hombres fueran buenos...", o, en otras palabras, si fuera posible creer en algo, sería mejor. Pero frente a la comprobación de una imposibilidad, hay una asunción plena de una realidad negativa, sin buscar en forma oportunista consuelos artificiales. Más que de cinismo, entonces -si queremos seguir con las metáforas filosóficas clásicas- habría que hablar, con mayor propiedad, de estoicismo.

Hay otro poema, en esta colección, que resulta importante, y tal vez decisivo, para comprender las raíces de la visión del mundo de Parra:

\title{
MOSCAS EN LA MIERDA
}

Al señor -al turista- al revolucionario

me gustaría hacerles una sola pregunta:

¿alguna vez vieron una nube de moscas

revolotear en torno a una plasta de mierda 


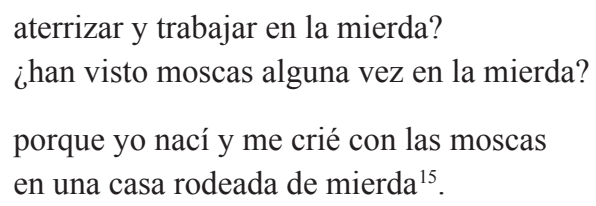

Es evidente en este texto la polémica hacia algunas profesiones superficiales o voluntaristas de fe política que no se basan en la experiencia real del dolor y la miseria. A la ideología abstracta se contrapone la vivencia material y áspera, que una vez más rechaza toda forma de idealización, reivindicando al contrario su brutalidad.

En el mismo libro, bajo el título "A propósito de escopeta", aparecen algunos breves poemas heterogéneos, entre ellos éste:

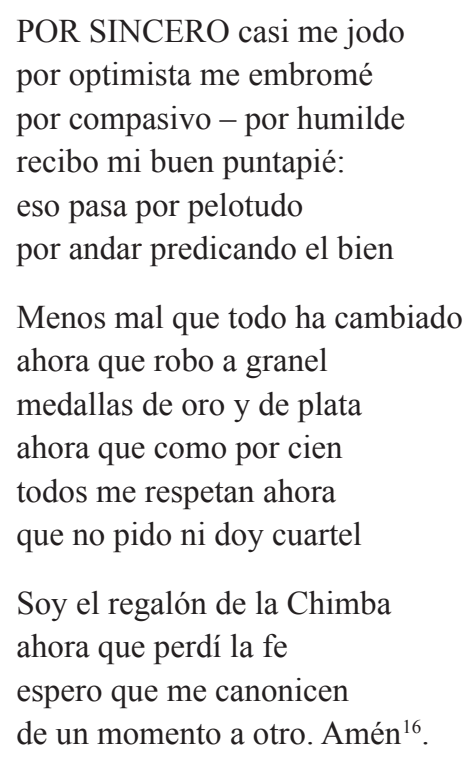

Al lado de estos textos parcialmente autoexegéticos, para comprender la personalidad profunda del poeta es importante también utilizar testimonios de personas que, en un momento de su vida, le fueron cercanas. A este

$\begin{array}{ll}15 & \text { Ibíd., p. } 21 . \\ 16 & \text { Ibíd., pp. } 80-81 .\end{array}$ 
propósito, disponemos de una página magistral que se debe a otro gran escritor hispanoamericano, José María Arguedas. En los "Diarios" que representan el contrapunto de la narración en su última novela El zorro de arriba y el zorro de abajo, sellada por el suicidio, encontramos una rendición de cuenta con la literatura hispanoamericana de los sesenta, donde aparecen sintonías y distonías. Pero encontramos también un retrato entrañable de los hermanos Parra, en cuya casa vive durante una fase dramática de su vida:

Pienso en este momento en Nicanor Parra, ¡cuánta sabiduría, cuánta ternura y escepticismo y una fuerte coraza de protección que deja entrar todo pero filtrando, $y$ una especie no de vanidad sino de herida abierta para las opiniones negativas de su obra! ; Qué modo increíble de ponerse amargo e iracundo por esas cosas! En la ciudad, amigos, en la ciudad yo no he querido creo que a nadie más que a Nicanor ni me he extraviado más de alguien que de él. Pero, ¿por qué tengo que decir estas cosas de Nicanor? Mucha ciudad tenía adentro o tiene adentro ese caballero tan mezclado y nacido en pueblo, el más inteligente de cuantos he conocido en las ciudades. ¡Lo que hablaba, sabía y no sabía o no sabe de las mujeres! ${ }^{17}$

A través de la relación simpatética establecida con el poeta (y con su hermano Roberto), Arguedas capta algunos rasgos profundos de su personalidad y de su obra. La herida abierta y la amargura representan el eje de este perfil, tales como se las encuentra, por ejemplo, en un poema como "Ritos", incluido en Canciones rusas:

Cada vez que regreso

A mi país

después de un viaje largo

Lo primero que hago

Es preguntar por los que se murieron:

Todo hombre es un héroe

Por el sencillo hecho de morir

Y los héroes son nuestros maestros.

17 J. M. Arguedas. El zorro de arriba y el zorro de abajo. Obras completas. Lima: Editorial Horizonte, 1983, t.V, p. 23. 
Y en segundo lugar

por los heridos.

Sólo después

no antes de cumplir

Este pequeño rito funerario

Me considero con derecho a la vida:

Cierro los ojos para ver mejor

$\mathrm{Y}$ canto con rencor

Una canción de comienzos de siglo ${ }^{18}$.

El hombre es malo, pero a pesar de todo, es asimismo un ser vulnerable, destinado al sufrimiento y a la muerte, y por eso despierta la compasión, en el sentido etimológico de padecer juntos. No estamos muy lejos, desde el punto de vista de la actitud, del célebre poema de César Vallejo "Considerando en frío, imparcialmente", donde la comprobación objetiva de la miseria humana (del "lóbrego mamífero") desemboca en un abrazo:

Considerando sus documentos generales y mirando con lentes aquel certificado que prueba que nació muy pequeñito...

le hago una seña, viene, y le doy un abrazo, emocionado.

¡Qué más da! Emocionado...Emocionado...19

La nota peculiar de Parra en el poema citado, sin embargo, es el "rencor" que acompaña la emoción y la matiza. Pero en esta tensión entre sentimientos opuestos (o tal vez complementarios) encontramos tal vez el secreto de la poesía (o antipoesía) de Parra. En ella no aparece la mirada resentida del que se ha quedado más acá de un umbral que quería pasar. La suya es, en cambio, la nostalgia sin esperanza del que ingresó en el mundo de las palabras encantadas, averiguando su disolución frente al horror de lo moderno.

$18 \quad$ N. Parra. Obra gruesa, cit., p. 107.

19 C. Vallejo. Obras completas, t. I, Obra poética, Ed. R. González Vigil. Lima: Banco de Crédito del Perú, 1991, pp. 530-531. 


\section{BIBLIOGRAFÍA}

Arguedas, José María. El zorro de arriba y el zorro de abajo. Obras completas. Lima: Editorial Horizonte, 1983, t. V. 9-219.

Machiavelli, Niccolò. Il Principe [1514]. Milano: Mondadori, 1994.

Melis, Antonio. "Nicanor Parra: l'antipoeta fino in fondo". Ruggiero Romano. L'Italia, l'Europa, l'America. Ed. Alberto Filippi. S. Severino Marche: Editrice Berta 80, 2000. 439-449.

"Un Re Lear cileno: Nicanor Parra". Testo, metodo, elaborazione elettronica.

Eds. Domenico Antonio Cusato, Domenica Iaria, Rosa Maria Palermo. Messina: Andrea Lippolis Editore, 2007. 263-276.

"Eros e Thanatos nella poesia di Nicanor Parra". Testo, metodo, elaborazione elettronica. Erotismo. Ed. Anita Viola. Messina: Andrea Lippolis Editore, 2014. 181-192.

Monterroso, Augusto. Viaje al centro de la fábula [1981]. Barcelona: Muchnik Editores, 1990.

Parra, Nicanor. Cancionero sin nombre. Santiago de Chile: Nascimento, 1937. Poemas y antipoemas [1954]. Ed. de René de Costa. Madrid: Ediciones Cátedra, 1988. Obra gruesa [1969]. Santiago de Chile: Editorial Andrés Bello, 1983. Artefactos. Santiago de Chile: Ediciones Nueva Universidad, 1972. Hojas de Parra. Santiago de Chile: Ediciones Ganymedes, 1985.

Schopf, Federico. "La escritura de la semejanza en Nicanor Parra". Revista Chilena de Literatura 2-3 (1970): 43-132.

Del vanguardismo a la antipoesía. Ensayos sobre la poesía en Chile [1986]. Santiago de Chile: LOM Ediciones, 2000.

Vallejo, César. Obras completas. T. I, Obra poética. Lima. 